\title{
The development of antioxidant peel-off facial masks from cinnamon bark extract (Cinnamomum burmannii)
}

\author{
Sani Ega Priani*, Restianti Mutiara, Dina Mulyanti \\ Pharmacy Department, Bandung Islamic University (UNISBA) \\ Taman Sari 1, Bandung, Indonesia
}

Submitted: 24-09-2019

Reviewed: 18-11-2019

Accepted: 08-03-2020

\begin{abstract}
The bark of cinnamon (Cinnamomum burmannii) contains cinnamaldehyde and other active substances with potent antioxidant properties. Antioxidants are effective at preventing and reducing UV-induced skin damages and skin aging. This study was intended to formulate and characterize the antioxidant peel-off facial masks containing cinnamon bark extract and the combination of polyvinyl alcohol (PVA) and hydroxypropyl methylcellulose (HPMC) as gelling agents. The ethanol extract of cinnamon bark and the developed peel-off mask were evaluated for their antioxidant activities by the $\alpha, \alpha$-diphenyl- $\beta$-picrylhydrazyl (DPPH) free radical scavenging method and for their physical characteristics. The cinnamon bark extract exhibited a very strong antioxidant activity, as evidenced by $\mathrm{IC}_{50}=10.04 \pm 0.08 \mathrm{ppm}$. As for the formulated peel-off mask, it had excellent physical characteristics, which were identified during organoleptic observations and $\mathrm{pH}$, viscosity, spreadability, and film drying time evaluations. Similar to its constituent extract, this mask produced significantly potent antioxidant effects, with $\mathrm{IC}_{50}=47.31 \pm 1.47 \mathrm{ppm}$. For these reasons, peel-off facial masks containing cinnamon bark extract have not only excellent physical characteristics but also powerful antioxidant properties.
\end{abstract}

Keywords: peel-off mask, cinnamon bark, ethanol extract, antioxidant

\footnotetext{
*Corresponding author:

Sani Ega Priani

Pharmacy Department, Bandung Islamic University (UNISBA)

Taman Sari, 1 Bandung, Indonesia

Email: egapriani@gmail.com
} 


\section{INTRODUCTION}

Cinnamomum burmannii Nees ex. Bl., commonly known as Indonesian cinnamon or Padang cassia, grows in Southeast Asia and is cultivated in parts of Indonesia and the Philippines. $C$. burmannii stem bark (or cinnamon bark) contains cinnamaldehyde and other active substances that reportedly have antioxidant properties (Al-Dhubiab et al., 2012; Vishnuvardhanaraj et al., 2013; Singh et al., 2007). Previous research confirms that the ethanol extract of cinnamon bark is a highly effective antioxidant with an Inhibitory Concentration $\left(\mathrm{IC}_{50}\right)$ of $<50 \mathrm{ppm}$ (Priani et al., 2014). Antioxidants are effective in preventing and reducing skin damages and aging due to exposure to UV lights. Also, antioxidant compounds can eliminate free radicals and decelerate oxidation and, when applied topically to the skin, can prevent UV-induced oxidative damages (Pandel et al., 2013; Godic et al., 2014).

Previous studies have developed emulsion gel containing black seed oil and proven their antioxidant and UV-protection properties (Priani et al., 2014; Priani et al., 2014). In this study, another dosage form was prepared for non-daily application with high occlusive capacity, namely, peel-off facial masks. Facial masks are one of the topical preparations with many beneficial effects, including skin whitening, skin moisturizing, and freckle removal. Meanwhile, peel-off masks are a kind of facial mask composed of film-forming polymers, such as polyvinyl alcohol or polyvinyl acetate, that create a cohesive plastic layer after entirely dried, allowing manual removal from the skin without leaving any residues. These preparations provide moisturizing action and enhance the effect of active compounds on the epithelium owing to the occlusive reaction caused by plastic polymeric layers (Berigh et al., 2013; Vieria et al., 2009).

The objective of this research was to formulate peel-off facial masks from cinnamon bark extract with excellent physical characteristics and potent antioxidant activities. These facial masks can be used as herbal cosmetic preparations.

\section{MATERIALS AND METHOD \\ Materials}

The plant materials used in this research were collected from Manoko (the Province of Jawa Tengah, Indonesia) and determined by the Herbarium Bandungense, ITB.

\section{Methods}

\section{Preparation of cinnamon bark extract}

The stem bark was dried, ground into powder, and then extracted by the maceration process using $96 \%$ ethanol with a 1:3 ratio. The maceration was carried out for 24 hours, at room temperature, and with three replicates. Afterward, the extract solution was evaporated in a vacuum rotary evaporator at $40^{\circ} \mathrm{C}$ and $220 \mathrm{mBar}$ (Priani et al., 2014). Preliminary screening of secondary metabolites, such as alkaloids, flavonoids, saponins, quinone, tannin, terpenoids, polyphenol, and steroids, was conducted according to the conventional phytochemical methods (Fransworth, 1966).

\section{Antioxidant activity test of the cinnamon bark extract}

The extract was tested for its antioxidant activity by the DPPH method. A DPPH solution (40 ppm, $2 \mathrm{~mL}$ ) was mixed with $2 \mathrm{~mL}$ of the ethanol extract solution at various concentrations $(5,10,20$, 30 , and $40 \mathrm{ppm}$ ). An equal amount of ethanol was then added to the control DPPH. After 30 minutes of incubation, the absorbance of this mixture was read at $514 \mathrm{~nm}$. The \% inhibitions of DPPH, free radicals, were calculated using the following equation:

$$
\% \text { inhibition }=\frac{\text { Abs control }- \text { Abs Sample }}{\text { Abs control }} \times 100 \%
$$

where Abs control is the absorbance value of the control DPPH solution and Abs Sample is the absorbance of the extract and DPPH solution. The extract concentration and \% inhibition were plotted to a graph to determine their linear regression equation. The results were expressed in $\mathrm{IC}_{50}$, i.e., the 
concentration of sample required to achieve 50\% inhibition of the DPPH free radicals (Molyneux et al., 2004).

\section{Preparation of peel-off facial mask from the cinnamon bark extract}

The composition of the peel-off mask formulated in this study is shown in Table I. Firstly, the stock gel was prepared by dispersing PVA and HPMC in heated purified water $\left(90^{\circ} \mathrm{C}\right)$ separately. Secondly, the cinnamon bark extract, methylparaben, and propylparaben were dissolved in propylene glycol. Finally, the solution and the remaining compounds were added to the gel then stirred continuously using a digital stirrer (Suheri et al., 2016).

Table I. The formulation of facial peel-off masks from the cinnamon bark extract

\begin{tabular}{cc}
\hline Ingredients & $\begin{array}{c}\text { Percentage in } \\
\text { Masks (\%) }\end{array}$ \\
\hline Cinnamon extract & 1 \\
PVA & 12 \\
HPMC & 1 \\
Propylene glycol & 5 \\
Glycerin & 5 \\
Methylparaben & 0.2 \\
Propylparaben & 0.05 \\
Purified water until & 100 \\
\hline
\end{tabular}

\section{Physical evaluation of the peel-off facial mask}

The peel-off mask gel was observed organoleptically (color, odor, and homogeneity) and evaluated for its $\mathrm{pH}$, viscosity, spreadability, and film drying time.

Homogeneity Test

The gel was applied to the surface of a slide then pressed using another. Its homogeneity was observed under a microscope.

\section{Viscosity Test}

The viscosity of the gel was determined using a Brookfield RV viscometer with a spindle number of 15 at $10 \mathrm{rpm}$.

Spreadability Test

About 1 gram of the mask gel was placed on a glass sized $20 \times 20 \mathrm{~cm}$. Afterward, the sample was closed with another glass, pressed with a predefined mass until the total weight reached $125 \mathrm{~g}$, and allowed to stand for $60 \mathrm{~s}$. Then, the diameter of the gel spread was measured (Hanum and Lia, 2016).

Film Drying Time Measurement

About 1 gram of the sample was spread over a glass plate $(5.0 \times 2.5 \mathrm{~cm})$ to create a uniformly thin layer, i.e., $1 \mathrm{~mm}$ in thickness. The glass plate was heated in an oven at $36.5 \pm 2.0{ }^{\circ} \mathrm{C}$, which simulated the temperature of the human body. The formulations were monitored until the drying process was completed and the film could be entirely removed from the glass slide (Vieira et al., 2009).

\section{Antioxidant activity test of the peel-off facial mask}

The peel-off facial mask was tested for its antioxidant activity by the same method as the extract, which was until the $\mathrm{IC}_{50}$ value of the preparation was obtained. 


\section{RESULTS AND DISCUSSION}

Cinnamon bark was extracted by maceration using a universal solvent (ethanol), and the yield of this extraction was $27.28 \%$. The phytochemical screening results of the stem bark powder and the extract were presented in Table II. This table shows that both the powder and extract contain various secondary metabolites, such as alkaloids, flavonoids, saponins, tannins, quinones, terpenoids, and steroids, all of which are medicinally important. Flavonoids and polyphenols are the compounds responsible for the antioxidant activity of cinnamon bark (SA et al., 2015).

Table II. The phytochemical screening of the cinnamon bark sample and its extract

\begin{tabular}{ccc}
\hline Class of compounds & $\begin{array}{c}\text { Powder of } \\
\text { stem bark }\end{array}$ & $\begin{array}{c}\text { Ethanol } \\
\text { extract }\end{array}$ \\
\hline Alkaloids & + & + \\
Flavonoids & + & + \\
Saponins & + & + \\
Tannins & + & + \\
Quinones & + & + \\
Polyphenol & + & + \\
Monoterpenes and sesquiterpenes & + & + \\
Steroids and triterpenoids & + & + \\
\hline
\end{tabular}

$(+)=$ Presence of constituents

The cinnamon bark extract was developed into peel-off masks. PVA, used as the film-forming agent, can enhance the adhesive capacity of the preparation. Its concentration can influence the viscosity, performance of film formation, film thickness after drying, and applicability of the mask. Meanwhile, HPMC was used to enhance the viscosity of the gel (Berigh et al., 2013; Priani et al., 2015). Based on the physical evaluation results presented in Table III, the peel-off facial mask produced had excellent physical characteristics. Also, the acidity/alkalinity of the gel corresponded to the $\mathrm{pH}$ of the face skin (4.5-6.5). As for spreadability, the gel was categorically optimum because the diameter of the spread was in the range of $5-7 \mathrm{~cm}$. Furthermore, the film drying evaluation revealed that the time required by the peel-off mask to become entirely dried was optimum, i.e., <30 min (Wendtner et al., 2006; Garg et al., 2002, Vieira et al., 2009).

Table III. The physical characteristics of the peel-off facial mask

\begin{tabular}{cc}
\hline Parameters & Results \\
\hline Organoleptic & Transparent brown color, with the faint odor of \\
& cinnamon \\
$\mathrm{pH}$ & $5.92 \pm 0.09$ \\
Viscosity & $7233.33 \pm 513.16 \mathrm{cps}$ \\
Homogeneity & Homogeneous \\
Spreadability & $6.10 \pm 0.10 \mathrm{~cm}$ \\
Film Drying Time & $19.00 \pm 1.73 \mathrm{~min}$ \\
\hline
\end{tabular}

The antioxidant activity test was conducted by measuring the inhibition of 2,2-diphenyl-1picrylhydrazyl (DPPH) free radicals. In the DPPH free radical scavenging assay, when antioxidants react with the DPPH, it changed the color of the mixture from purple to yellow (a-diphenyl- $\beta$-picryl hydrazine). The degree of discoloration indicates the radical-scavenging potential of the sample. DPPH assay is one of the most popular antioxidant assays chiefly because it is simple, relatively inexpensive, quick, and efficient (Molyneux et al., 2004). 
Table IV. The $\mathrm{IC}_{50}$ values of the cinnamon bark extract and peel off facial mask

\begin{tabular}{ccc}
\hline Samples & $\begin{array}{c}\text { Regression } \\
\text { equation }\end{array}$ & IC $_{\mathbf{5 0}}$ values (ppm) \\
\hline Cinnamon bark extract & $\mathrm{y}=3.69 \mathrm{x}+11.48$ & $10.04 \pm 0.08$ \\
$\begin{array}{c}\text { Cinnamon peel-off facial } \\
\text { mask }\end{array}$ & $\mathrm{y}=10.04 \pm 0.08$ & $47.31 \pm 1.47$ \\
\hline
\end{tabular}

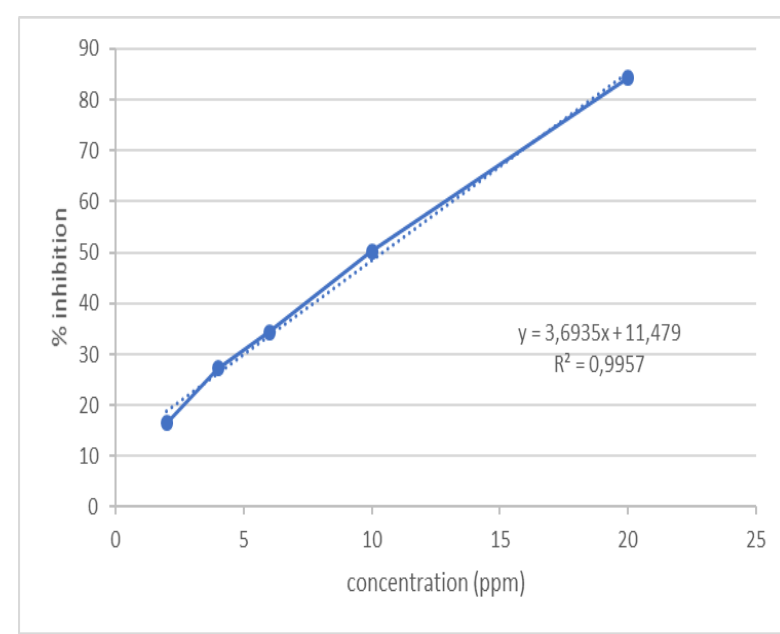

(a)

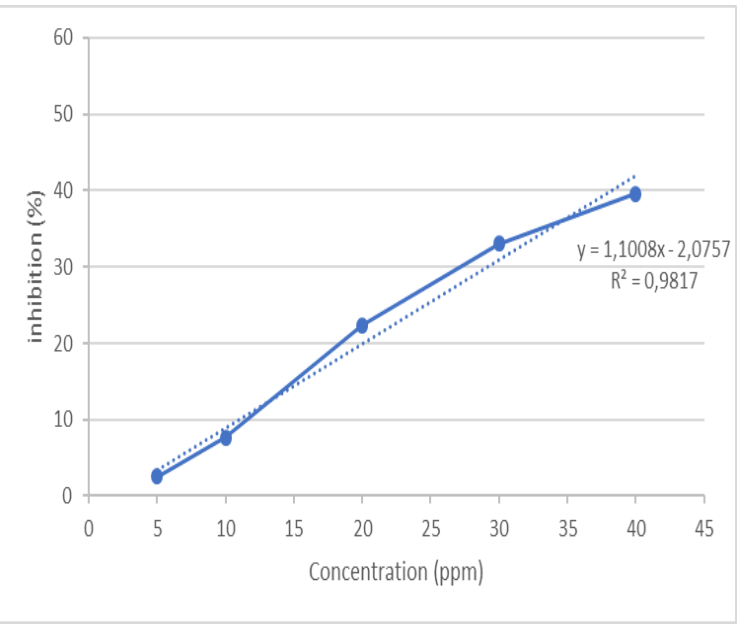

(b)

\section{Figure 1. The calibration curves of the antioxidant activity tests of (a) cinnamon bark extract and (b) cinnamon peel-off facial mask}

The cinnamon bark extract and the peel-off mask produced $\mathrm{IC}_{50}$ values of $10.04 \pm 0.08$ and 47.31 $\pm 1.47 \mathrm{ppm}$, respectively (Table IV, Figure 1), indicating powerful antioxidants ( $\mathrm{IC}_{50}$ less than 50 ppm) (Shetta et al., 2013). The antioxidant effect of this extract is believed to be the product of its bioactive constituents, including cinnamaldehyde, cinnamic acid, eugenol, polyphenol, and procyanidin (Rao et al., 2014). From the test results, the peel-off facial mask formulated from cinnamon bark extract is concluded to have significant potential as cosmetic preparations. With potent antioxidant properties, it can treat the skin and prevent premature aging. Antioxidants are compounds that can counteract or reduce the negative impact of oxidants on the skin. Propylene glycol at the preparation can act as a penetrant enhancer that improves the infiltration of active antioxidant substances through the skin. It also functions as a chemical penetrant enhancer by improving the partitioning of drugs into the stratum corneum (Haque et al., 2018).

\section{CONCLUSION}

The peel-off facial mask formulated from cinnamon bark extract has excellent physical characteristics, as evidenced by organoleptic observation and $\mathrm{pH}$, viscosity, spreadability, and film drying time evaluations. Cinnamon bark extract and the peel-off facial mask prepared from it have highly potent antioxidant properties, with the $\mathrm{IC}_{50}$ of $10.04 \pm 0.08$ ppm and $47.31 \pm 1.47 \mathrm{ppm}$, respectively. 


\section{ACKNOWLEDGMENT}

The authors would like to thank the Pharmacy Department of UNISBA for facilitating this research.

\section{REFERENCES}

Al-Dhubiad, B.E., 2012, Pharmaceutical applications and phytochemical profile of cinnamomum burmannii, Article Pharmacognosy Review, 6 (12): 125-131.

Berighs, A.O., Julia, M.R., Hellen, K.S., 2013, Green clay and aloe vera peel-off facial masks: response surface methodology applied to the formulation design, American Association of Pharmaceutical Scientists, 4(1): 445-455.

Fransworth, N.R., 1966, Biological and phytochemical screening of plants, Journal of Pharmaceutical Sciences, 55(3): 225-240

Garg, A., Aggarwal, D., Garg, S., Singla, A.K., 2002, $\quad$ Spreading of semisolid formulations A update, Pharmaceutical Technology North America, 26(9):84-105.

Godic, A., Borut, P., Metka, A., 2014, The Role of Antioxidants in Skin Cancer Prevention and Treatment, Oxidative Medicine and Cellular Longevity, 2014: 1-7.

Haque, T., Talukder, M.M.U., 2018, Chemical Enhancer: a simplistic way to modulate barrier function of the stratum corneum, Advanced Pharmaceutical Bulletin, 8(2):169-179.

Hanum, I.T., Lia, L., 2016, Physical Evaluation of Anti-aging and Anti-acne Andaliman (Zanthoxylum acanthopodium DC.) Ethanolic Extract Peel Off Gel Mask, Der Pharma Chemica, 8(23):6-10.

Molyneux, P., 2004, The use of the stable free radical diphenylpicrylhydrazyl (DPPH) for estimating antioxidant activity, Journal of Science and Technology, 6(2): 211-219.

More, B.H., Sakharwade, S.N., Tembhurne, S.V., 2013, Evaluation for irritancy testing of developed formulations containing extract of Butea monosperma for its topical application, International Journal of Toxicology and Applied Pharmacology, 3(1): 10-13.

Pandel, R., Borut, P., Aleksandar, G., Raja, D., 2013, Skin photoaging and the role of antioxidants in its prevention, International Scholary Research Notice Dermatology, 2013: 1-11.

Priani, S.E., Fitrianti, D., Haniva, H., 2014, Formulasi sediaan emulgel antioksidan mengandung ekstrak etanol kulit buah manggis, Prosiding Seminar Nasional Penelitian dan Pengabdian pada Masyarakat (SNaPP) Kesehatan (Kedokteran, Kebidanan, Keperawatan, Farmasi, Psikologi), 4(1): 103-110.

Priani, S.E., Fitrianti, D., Haniva, H., 2014, Development of sunscreen emulgel containing Cinnamomum burmannii stem bark extract, International Journal of Science and Research, 3(13): 2338-2339.

Priani, S.E., Irma, I., Fitrianti, D., 2015, Formulasi Masker Gel Peel-Off Kulit Buah Manggis (Garcinia mangostana Linn.), Indonesian Journal of Pharmaceutical Science and Technology, 2(3): 90-95.

Rao, P.V., Siew, H.G., 2014, Cinnamon: a multifaceted medicinal plant, Evidence Based Complement Alternative Medicine, 2014: 1-12.

SÁ, A., Rosso, Sibele, Ferreira, Sandra, 2015, Antioxidant activity and chemical composition of Supercritical and conventional extract of cinnamon, Conference: xx Congresso Brasileiro de Engenharia Química: 1-8.

Setha, B., Febe, F.G., Andi, P.S., Idris, Samsul, R., Meigy, N.M., 2013, Potential of seaweed Padina sp. as a source of antioxidant, International of Scientific and Technology Research, 2(6): 2013, 221-224.

Suhery, W.N., Nia, A., 2016, Formulation and evaluation of peel-off gel masks from red rice bran extract with various kind of bases, International Journal of PharmTech Research, 9(12): 574580 . 
Singh, G., Maurya, S., DeLampasona, M.P., Catalan, C.A., 2007, A comparison of chemical, antioxidant and antimicrobial studies of cinnamon leaf and bark volatile oils, oleoresins and their constituents, Food Chemical Toxicology, 45(9): 1650-1661.

Vieira, R.P., Alessandra R.F., Telma, M.K., Vladi, O.C., 2009, Physical and physicochemical stability evaluation of cosmetic formulations containing soybean extract fermented by bifidobacterium animalis, Brazilian Journal of Pharmaceutical Sciences, 45(3): 515-525.

Vishnuvardhanaraj, G., Tamilvendan, D., Amaladasant, M., 2013, Synthesis, characterization, and biologycal activities of cinnamaldehydes mannich base, International Journal of Pharmacy and Pharmaceutical Sciences, 5(3): 821-825.

Wendtner, M.H., Korting, H.C., 2006, The pH of the skin surface and its impact on the barrier function, Skin Pharmacol Physiol, 19(6): 296-301. 
